inner city multiracial environment we are familiar with the difficulties caused by hidden prejudices. Though prejudice towards women in medicine may come from within the medical profession, patients may also be reluctant to consult women doctors, giving rise to another, hidden, difficulty for women doctors.

We examined this possibility in a survey of 100 consecutive patients attending a rheumatology outpatient clinic in Hackney. We used a structured questionnaire to determine whether patients wanted to see male/female, old/young, or senior/ junior doctors. for their rheumatology consultation. The table summarises the results.

Type of doctor preferred by 100 patients attending a rheumatology clinic

\begin{tabular}{lc}
\hline Characteristics of doctor & Preferences \\
\hline Sex: & \\
Male & 5 \\
Female & 5 \\
No preference & 90 \\
Age: & 26 \\
>35 years & 2 \\
<30 years & 73 \\
No preferences & 63 \\
Rank: & 3 \\
Consultant & 35 \\
Junior & No preference \\
\hline
\end{tabular}

Most patients wanted to see a consultant. There was also a preference for seeing an older doctor. Both were considered to be more experienced. By contrast, only $10 \%$ expressed any preference for seeing a male or female doctor; these were divided equally. When patients were asked, however, whether they would be more likely to follow advice given by a male or female doctor there was some bias: 10 patients considered that they would take advice better from a man, and two from a woman, and 88 had no preference.

Whatever the hidden difficulties that women encounter in pursuing a career in hospital medicine it is reassuring that in our district there is no evidence to suggest that patients have strong views on whether they see a male or female doctor. This contrasts with their clearcut wish to see a consultant. Rheumatology is not comparable with specialties like gynaecology, where patients may be more likely to prefer one sex to another. Hackney is also an inner city area, which is not typical of many parts of south east England. Nevertheless, our findings should allay the fear, implied at the end of Dr Begley's Personal View, that potential patients do not think of women as doctors.

Susan Catnach

DAVID L SCOTT

Homerton Hospital,

London E9 6SR

\section{Measuring performance or balancing the budget}

SIR,-Though general management is bringing new ideas to the National Health Service, some of these are being applied in a dangerously simplistic way. The performance indicator group at the Department of Health and Social Security has recently published for consultation a series of papers on performance indicators in different areas of medicine (15 August, $p$ 451). They are intended to measure management efficiency in attaining objectives and may well, in the near future, have a direct effect on the allocation of funds to management units. They could also eventually be extended to clinical practice.

The performance indicators seem to be flawed in two main ways. Firstly, they do not attempt to measure quality of output, which is surely essential if the claim is to measure performance rather than workload. Secondly, even as measures of workload they are grossly inadequate because they are based on the Körner data set, which, though an improvement on earlier data sets, itself fails to consider some important items of work.

To take an example from psychiatry, the only community work recorded is visits by community psychiatric nurses. Yet in some types of psychiatry (notably old age psychiatry) home assessment is used for over three quarters of referrals. In addition, a substantial number of psychiatric referrals are seen on non-psychiatric wards in hospital as liaison referrals; again, they are not counted as only psychiatric outpatient, day hospital, and inpatient work appears (however inadequately) in the Körner data set.

Other areas of medicine are also affected. For example, it seems that the work of a senior surgeon supervising his junior is disregarded, and educational activity seems not to be monitored at all The performance indicators group at the Department of Health and Social Security is aware of the limitations of basing performance indicators on the Körner data set, but the danger is that financial managers at the regional and district level will be misled by the title performance indicators into thinking that they really do measure performance.

Any industry that decided to assess its performance on criteria that measured only a variable fraction of its workload and failed to consider quality of outcome at all would not survive long. There is certainly a place for true performance indicators in health service management, but the proposed inadequate set might do more harm than good.

St James's University Hospital

JOHN P WATTIS

Leeds LS9 7TF

SIR,-The consultation period for performance indicators in the National Health Service, derived from the Körner data sets, ended on 25 September $1987,{ }^{1}$ but "the data sets have taken a stab at the sort of data the NHS will need to consider without defining the purposes for which it is required."2 It therefore comes as no surprise that the proposed performance indicators describe a severely restricted range of clinical activity because of the limitations of Körner and the difficulty in defining outcomes that reflect performance. Is the performance indicator group to be congratulated?

We have measured the activity of our psychiatry of old age service since its inception three years ago using a modification of the data described in The Rising Tide. ${ }^{3}$ The proposed performance indicators do not detect patients who are treated solely within the community or those referred for hospital liaison. As this is the first point of contact with the service the $\mathbf{3 0 0}$ new patients seen each year are not indicated unless they subsequently occupy a hospital bed or attend the day hospital. Of the 300 patients currently receiving treatment, only $55 \%$ meet these criteria. The activity of professions such as occupational therapy and physiotherapy is measured as a district aggregate rather than in relation to specific clinical services, and the contribution of social workers, who are part of the multidisciplinary team, is ignored because they are not National Health Service employees.

Our district has a reputation for pioneering management techniques, as evidenced by monthly statements of clinical budgeting, describing both activity and expenditure. It is expected that the current climate of management by consultation and negotiation will be sustained despite projections of substantial overspending in the district budget. In districts where clinical services do not accurately measure their activity or a climate of mistrust exists between clinicians and managers the prospect of inaccurate performance indicators being used to impose cuts in clinical services is resulting in the winds of change once more fuelling the fires of resistance.

North Tees General Hospital

Nigel TYRe Cleveland TS19 8PE

1 Performance Indicator Group. Performance indicators for the NHS. London: Department of Health and Social Security, 1987.

2 Windsor P. Introducing Körner. Surrey: British Journal of Health Care Computing, 1986:12.

3 Health Advisory Service. The rising tide. Surrey: Health Advisory Service, 1982.

\section{What patients put up with}

SIR,-I was pleased that Dr Doug Addy found Clive Jermain, the young sufferer from a spinal tumour who wrote a television play about his experiences, to be intelligent, mature, quick thinking, verbally fluent, and down to earth (12 September, p 661). I have known him for five years and find him to be all these things and more. He is charming, uncomplaining, and well adjusted, despite a life made stressful by the failure to diagnose his condition expeditiously.

In 1981 Clive managed to get hold of his hospital notes long enough to photocopy them. He gave a copy to me along with his own account of his illness. I would like to quote from both.

"At the age of 6 [Clive was born in 1965] I stepped off the kerb and was hit by a car. I was not hurt in the slightest and ran home, where I hid in the garden shed, frightened and shocked. Some months later I started to wake at night with neck and back pain. One night I was taken to our local hospital and $x$ rayed, but nothing was found."

Later, Clive was sent to an orthopaedic surgeon, who referred him to a psychiatrist- - "because at that stage my parents had split up it was put down as 'emotional upset."' The child psychiatrist admitted him to hospital. "After an agonising month seeing some horrific sights I was taken away by my father."

Two years later, still in constant pain, he was again referred to an orthopaedic surgeon, who diagnosed idiopathic scoliosis-normally a painless condition-and put him in a brace. This did not help, and neither did a week of traction. He had difficulty urinating and his legs gave way so often that, at the age of only 13 , he walked with a stick.

In 1978, seven years after the pain started, he was described in his notes as neurologically normal. He had an operation to produce spinal fusion from $\mathrm{T} 2$ to $\mathrm{L} 1$, with a Harrington rod between these vertebrae. After this he had severe back and neck pain and loss of sensation and movement in his right hand. The diagnosis was still idiopathic juvenile scoliosis.

By 1980 he was partly paralysed with loss of sensation in his hand and wasting in his right leg, but his notes say, "The features of cord compression if any are nevertheless not striking." He was referred to the psychiatrist again, despite Clive's father's "total prejudice against psychiatrists ... Mr Jermain refuses to entertain the idea that there may be emotional problems." The diagnosis was still idiopathic juvenile scoliosis.

By early 1981 the diagnosis was a "high thoracic cord lesion," and he was told he might not walk again. The psychiatrist wrote of "family and school disturbance... I am sure his apprehension and preoccupation are increasing his sensitivity to pain... Valium might help him at night."

He spent several weeks in a neurological ward, though he was temporarily transferred to another hospital for radiotherapy. After the radiotherapy finished he was transferred back to the neurology

\title{
.
} .

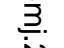

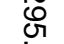

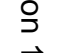

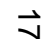
음 (t)

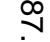


ward of the previous hospital, where he remembers being dragged to physiotherapy despite a severe chest infection. At this point the Harrington rod penetrated the skin of his neck and he had to go back into hospital to have the end snipped off.

He was sent home with a chest infection and an indwelling catheter; after six weeks the chest infection, diagnosed by his general practitioner as bronchial pneumonia, cleared; at this point he developed a urinary infection. A fellow patient he had met on the ward told him how to tap his bladder to empty it completely. No one on the hospital staff had told him this.

By March 1981 a computed tomogram showed expansion of his upper cervical spinal cord, and a biopsy specimen taken at an exploratory operation in April produced "two pieces of densely gliotic soft tissue with numerous thin walled blood filled spaces, some of which are obliterated by hyaline connective tissue. The astrocytic cells surrounding the vessels are of varied size and shape; they are associated with abundant fine glial fibres and plentiful Rosenthal fibres."

There is then a gap in the record until December

\section{Drug points}

\section{Pseudomembranous colitis and tetracycline}

Drs A J Treloar and A N Hamlyn (Russells Hall Hospital, Dudley, West Midlands DY1 2HQ) write: Pseudomembranous colitis is caused by toxigenic Clostridium difficile. We report what we believe to be the first microbiologically confirmed link with ora tetracycline.

A healthy 51 year old white woman was given oral oxytetracycline for perioral dermatitis. She received $250 \mathrm{mg}$ four times daily for two weeks, then $250 \mathrm{mg}$ three times daily for two weeks, then $250 \mathrm{mg}$ twice daily for two weeks. She received no other drugs. In the final week of treatment she developed profuse watery diarrhoea. Management at home with diphenoxalate was unsuccessful, and she was referred for hospital care. On arrival she was feverish $\left(37 \cdot 7^{\circ} \mathrm{C}\right)$ and diffusely tender over the entire abdomen. Apart from soreness, rectal examination yielded negative results. Stool culture confirmed the presence of $C$ difficile with toxin production on culture and neutralisation of cytopathic effect by sordelli antitoxin Treatment included general supportive measures and oral metronidazole, $800 \mathrm{mg}$ three times daily for five days followed by $\mathbf{4 0 0} \mathrm{mg}$ three times daily for seven days. Her symptoms resolved, and stool cultures became negative. She was allowed to go home but relapsed three weeks later. Stool culture again yielded toxigenic $C$ difficile. Fibresigmoidoscopy and biopsy at this stage confirmed typical pseudomembranous colitis. She was treated with oral vancomycin, $125 \mathrm{mg}$ four times daily for seven days, and symptoms again settled. For the next two months she had mild but persistent diarrhoea and stool cultures were intermittently positive for the same organism. These became negative with eventual resolution of her diarrhoea. Follow up fibresigmoidoscopy showed normal mucosa.

Pseudomembranous colitis is a dangerous and often fatal complication of antibiotic treatment. Lincomycin and clindamycin are the most frequently reported causative agents. ${ }^{1}$ It has not been reported in association with tetracyclines since 1952, when microbiological evidence was unavailable. Then four patients treated with chlortetracycline were found to have what we now know to be histological and macroscopic evidence of pesudomembranous colitis. ${ }^{2}$ In 1953 five patients given tetracyclines were reported to have developed "non-specific ulcerative colitis." 3 These reports were published long before the association of pseudomembranous colitis with toxigenic $C$ difficile was recognised. ${ }^{45}$ The specific diagnosis of pseudomembranous colitis is based on the finding of toxigenic $C$ difficile, and its association with many antibiotics is well established. ${ }^{14}$ The Committee on Safety of Medicines, however, has had no reports of pseudomembranous colitis in association with tetracycline (personal communication). Our patient developed a
1981, when a letter to the occupational therapist read, "It was not until this year that the diagnosis of a cervical hamartoma was made at operation. This tumour is an integral part of the spinal cord and could not be removed but he had postoperative irradiation in the hope that this would lessen the progression of his signs. Unfortunately postoperatively he showed evidence of a profound tetraparesis."

In 1981, after 10 years of severe pain, Clive's umour was diagnosed at biopsy as a hamartoma (at C5-6)-so it seems he has neurofibromatosis in one of its less typical forms.

At the time his programme was broadcast he was in hospital in a coma, but he made a splendid return to consciousness and has now returned home and to his job with the cancer charity Search 88. His exit from hospital was shown on BBC television news. All his many friends-and he has many-were delighted. I was especially happy, as two weeks earlier I had written his obituary with a heavy heart.

London SW15 INU

CAROLINE RICHMOND

potentially lethal condition as a result of treatment for a minor facial problem. The association between tetracyclines and pseudomembranous colitis is presumably rare, but recognition that it may occur with this group of antibiotics is clearly important, and we suggest that it is more common than a single case report would suggest. This could be shown only by a large prospective study of the use of tetracycline or by further notifications to the Committee on Safety of Medicines. Patients who develop diarrhoea as a result of antibiotic treatment should always have stool cultures performed before being given non-specific antidiarrhoeal remedies.

Davies DM. Textbook of adverse drug reactions. 2nd ed. Oxford: Oxford University Press, 1981:204.

2 Reiner L, Sclesinger MJ, Miller GM. Pseudomembranous colitis followed aureomycin and chloramphenicol. Archives of Pathology 1952;54:39-67.

3 Klotz AP, Palmer WL, Kirsner JB. Aureomycin proctitis and colitis a report of five cases. Gastroenterology 1953;25:44-7.

4 Larson HE, Price AB, Honour P, Borriello SP. Clostridium difficile and the aetiogy of pseudomembranous colitis. Lancet 1978;i:1063-6.

5 George RH, Symmonds JM, Dimock F, et al. Identification of Clostridium difficile as a cause of pseudomembranous colitis. Br Med f 1978;i:695.

\section{Association of lofepramine with abnormal} liver function in elderly patients

Drs Graeme J A Macphee, Margaret A Roberts, and CATHERINE E MCKeAN (Victoria Infirmary, Glasgow G41 3DX) write: Lofepramine is a new tricyclic antidepressant drug.' We report on three elderly patients treated with this drug who developed increased liver enzyme activities without overt clinical features of hepatic dysfunction.

Results of liver function tests after treatment with lofepramine

\begin{tabular}{|c|c|c|c|c|c|c|}
\hline $\begin{array}{l}\text { Duration of } \\
\text { hospital stay } \\
\text { (weeks) }\end{array}$ & $\begin{array}{c}\text { Aspartate } \\
\text { aminotransferase } \\
\text { activity }(\mathrm{U} / \mathrm{l})\end{array}$ & $\begin{array}{c}\text { Alanine } \\
\text { aminotransferase } \\
\text { activity (U/1) }\end{array}$ & $\begin{array}{c}\gamma \text {-Glutamyl } \\
\text { transferase } \\
\text { activity }(\mathrm{U} / \mathrm{l})\end{array}$ & $\begin{array}{c}\text { Alkaline } \\
\text { phosphatase } \\
\text { activity (U/I) }\end{array}$ & $\begin{array}{c}\text { Bilirubin } \\
\text { concentration } \\
(\mu \mathrm{mol} / \mathrm{l})\end{array}$ & $\begin{array}{c}\text { Lofepramine dose } \\
\text { (mg/day) } \\
\text { (duration in weeks) }\end{array}$ \\
\hline $\begin{array}{r}7 \\
8 \\
9 \\
14\end{array}$ & $\begin{array}{r}23 \\
290 \\
22 \\
18\end{array}$ & $\begin{array}{r}27 \\
271 \\
85 \\
8\end{array}$ & $\begin{array}{l}\text { Case 1 } \\
150 \\
722 \\
444 \\
22\end{array}$ & $\begin{array}{l}350 \\
809 \\
571 \\
159\end{array}$ & $\begin{array}{l}11 \\
18 \\
13 \\
13\end{array}$ & $\begin{array}{c}210(2) \\
210(3) \\
0 \\
0\end{array}$ \\
\hline $\begin{array}{r}8 \\
9 \\
11 \\
15\end{array}$ & $\begin{array}{l}28 \\
61 \\
14 \\
15\end{array}$ & $\begin{array}{r}24 \\
65 \\
7 \\
13\end{array}$ & $\begin{array}{c}\text { Case } 2 \\
77 \\
256 \\
153 \\
51\end{array}$ & $\begin{array}{l}314 \\
757 \\
362 \\
219\end{array}$ & $\begin{array}{l}16 \\
22 \\
17 \\
13\end{array}$ & $\begin{array}{c}140(1) \\
140(2) \\
0 \\
0\end{array}$ \\
\hline
\end{tabular}

Normal values: aspartate aminotransferase activity: $<37 \mathrm{U} / \mathrm{l}$; alanine aminotransferase activity: $<40 \mathrm{U} / \mathrm{l} ; \gamma$-glutamyl transferase activity: women $<30 \mathrm{U} / \mathrm{h}$, men $<45 \mathrm{U} / \mathrm{l}$; alkaline phosphatase activity: $<260 \mathrm{U} / 1$; bilirubin concentration: women $<17 \mu \mathrm{mol} / 1$, men $<21 \mu \mathrm{mol} / 1$

A 90 year old woman with a left hemiparesis, who was receiving bendrofluazide $10 \mathrm{mg}$ and atenolol $100 \mathrm{mg}$, became depressed. Results of liver function tests were normal. Treatment was started with lofepramine $70 \mathrm{mg}$ daily and increased by weekly $70 \mathrm{mg}$ increments to $210 \mathrm{mg}$ daily. The table shows the results of liver function tests during and after treatment with lofepramine. Ultrasound assessment of he abdomen, a hepatic isotope scan, and tests for antibody to hepatitis B surface antigen, hepatitis A specific antibody, and cytomegalovirus all yielded rative results.

A 75 year old man was admitted with poor mobility and depression three months after a right hemicolectomy for adenocarcinoma. Six weeks later treat ment was started with lofepramine $70 \mathrm{mg}$ daily and increased to $140 \mathrm{mg}$ after one week. The results of liver function tests, which had previously been normal on two occasions, became abnormal, as shown in the table. Ultrasound assessment of the abdomen and a hepatic scan yielded normal results, as did serology for hepatitis. The patient remained well, with normal results of liver function tests, four months after treatment with lofepramine was withdrawn.

A 90 year old woman with Alzheimer's disease, who was receiving frusemide $40 \mathrm{mg}$, thyroxine $0.1 \mathrm{mg}$, flurbiprofen $100 \mathrm{mg}$, and thioridazine $70 \mathrm{mg}$ daily, developed depression. Liver function tests yielded normal results. Treatment was started with lofepramine $70 \mathrm{mg}$ and increased to $140 \mathrm{mg}$ after 10 days. After three days of treatment with lofepramine alkaline phosphatase activity rose to $322 \mathrm{U} / \mathrm{l}$; one week later this was $595 \mathrm{U} / \mathrm{l}$ and $\gamma$-glutamyl transferase activity was $122 \mathrm{U} / \mathrm{l}$. Aspartate aminotransferase activity was $114 \mathrm{U} / \mathrm{l}$ and alanine aminotransferase activity $116 \mathrm{U} / \mathrm{l}$. Bilirubin concentration remained normal. After treatment with lofepramine was stopped transaminases fell to normal over five days, while $\gamma$-glutamyl transferase and alkaline phosphatase activities reverted to normal over six weeks. Other treatment remained unchanged.

The temporal relation of deranged biochemistry with lofepramine treatment and its withdrawal strongly suggests a reaction to the drug. Though minor transient increases in liver enzyme activities, usually benign in nature, often occur with tricyclic drugs, ${ }^{2}$ serious hepatic injury may be induced by such drugs, including desmethylimipramine, the main metabolite of lofepramine. ${ }^{34}$ Accordingly, treatment was promptly stopped and diagnostic rechallenge was considered to be hazardous. The Committee on Safety of Medicines has received 35 reports of abnormal hepatic function, two of hepatitis, six of jaundice, two of hepatocellular damage, and one of hepatic failure associated with lofepramine (personal communication). Because lofepramine seems to have few anticholinergic side effects it may often be prescribed for elderly patients. Clinicians who treat such patients should be aware of the possible effect of lofepramine on hepatic enzymes.

Pugh R, Bell J, Cooper AJ, et al. Does lofepramine have fewer side effects than amitriptyline? I Affective Disord 1982;4: 355-63.

2 Blackwell B. Antidepressant drugs. In: Dukes MNG, ed. Meyler's side effects of drugs. Amsterdam: Elsevier, 1984:38.

Powell WJ, Weser JK, Williams RA. Lethal hepatic necrosis after therapy with imipramine and desipramine. JAMA 1968;

Price LH, Nelson JC, Waltrip RW. Desipramine associated hepatitis. f Clin Psychopharmacol 1982;3:243-6. 